\title{
Using Media Articles About Company Strategies To Teach Economics To MBA Students
}

Indranil K Ghosh, Saint Xavier University, USA

\begin{abstract}
In this paper, the author expands on the idea of using up-to-date examples to teach applications of economic concepts. In the MBA Managerial Economics class, the author use profiles of two companies' decision-making strategies and their successes to show the applications of economic concepts used by the companies. This provides an even clearer relationship between economics and the real world as students are able to follow the entire story of one company and relate different economic concepts that this firm has used during the part of their existence that is profiled. This provides a stronger link between the real life business world and economic concepts than before.
\end{abstract}

Keywords: Economic Education; Teaching Economics in Business Schools; Learning from Business Applications of Economic Concepts; Active Learning; Practical Applications; Real Life Businesses

\section{INTRODUCTION}

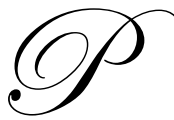

edagogical research in innovative teaching methods for economics courses has undergone a remarkable transformation (Becker and Watts, 2005, and Becker, Watts and Becker, 2006). This has been true for both undergraduates and for graduate MBA courses. As students become more reliant and dependant on innovative technology products, and become more entrenched in the social media revolution, they begin to start to demand teaching that is more in tune with all these technological innovations. Traditional chalk and talk methods as a pedagogical tool in all subjects are thus becoming less and less popular, as instructors respond to student needs and seek to engage students with interesting and challenging modes of instruction. A traditional "chalk and talk" pedagogical style tends to make students less and less interested in the happenings of the classroom and more likely to let their minds wander away to other thoughts. With the advent of smartphones and the use of laptops in the classrooms, students have every opportunity to tune out their boring "same old, same old" professor and hop onto the internet where they can easily peruse the happenings of the day, catch up with their friends on Facebook, Twitter and other social media, or could just carry on a text message conversation with their friends, some of whom might be sitting in the same classroom. In addition to this being problematic for all courses, economics courses have the rather unsavory reputation of being dry, boring, impossible to understand, too math and graph-oriented, too abstract with little real life applications, etc. The last comment is especially galling as the principal ideas of economics have everything to do with business, and it is really not too difficult to come up with hundreds of examples of applications of each economic concept. If you open the pages of any business news website or periodical, one can find a lot of current events that demonstrate some application of an economic concept.

Mark Maier and Scott Simkins (2009), in a fundamental piece of pedagogical work called Just in Time Teaching (JITT), provide insights into the use of assignments that students have to look at, grasp the concept of the questions and finish in just a few hours before class starts. Despite the obvious thoughts of slap dash work and corner cutting by students, the pedagogy actually helps students develop skills of introspection and persistence as well as innovation of thought. The idea behind this is really simple and practical - when students enter the real world and are employed, they will face innumerable just-in-time assignments. They will have to process the information and come up with strategies and solutions in just a few hours. Students in a classroom realize this, and the 
excitement of having a project or homework that resembles a real life work assignment, at least in terms of the time available, makes students more eager to engage in their course work. Following the JITT innovation, a previous paper (Ghosh and Rahman, 2011) explains the process of using cases and examples that are currently taking place in the real world and relating them as applications of an economic concept that is being taught in class. These cases and examples that were used were different from the examples that could be found in standard textbooks. A brief scan of the latest text in both Principles of Economics and MBA Economics courses reveals the following examples and cases:

- $\quad$ LeBron James choosing not to attend college (opportunity cost)

- $\quad$ Outsourcing to China (international trade)

- $\quad$ Pricing Tickets for Broadway shows (price discrimination

- $\quad$ FCC Auctions (Economics of information and uncertainty)

- The managerial perils of Asian chipmakers at the height of the tech boom (perfect competition)

Unfortunately, none of these examples can be called "just in time"; i.e., the stories in them have all taken place a while back. Students have thus either forgotten about these events and examples or they have never heard of them, hence their complaints about economics concepts having few real life examples. It is not that the concepts have few applications; it is that the students have no interest in examples that are not current. This was the basic motivation of using up-to-date and current examples in the classrooms to bring economic concepts to life.

This paper goes one step further. While specific examples that illustrate specific economic concepts proved to be quite successful in engaging students and making them aware of the practical applications of economic concepts, this does not have to be the only example that can be used in the classroom. The impact on students would be significantly stronger if instructors could use an example of a company or business in action that would relate different strategic decisions made by the company to different economic concepts. In the previous paper cited above, applications of direct price discrimination and prisoners' dilemma, for example, were described by citing the real life examples of Sams Club and its use of personalized coupons and the service competition between CVS and Walgreens. If an example of the different strategies used by a company that would relate different decisions made by this one company to different concepts taught in a standard economics class is used, it would provide a continuous stream of application of economic concepts. In this paper, a description of two different company strategy profiles (that are used in an MBA-level Managerial Economics class taught by the author, published in the business media, and freely available) are described, including the core concepts taught in the course, a brief description of the two media profiles of the two companies, and the different strategic decisions made by the companies based on different economic concepts. The paper also provides a description of the method of instruction used to relate the economic concepts to the decisions made by the companies.

\section{THE BASIC MBA MANAGERIAL ECONOMICS COURSE}

The course that is used to implement this innovative technique is the basic MBA level Managerial Economics course. Typically, most every MBA program includes either this course or some kind of variant. The goal of this course is usually to provide future business managers with an in-depth knowledge of economic concepts, especially their application to real life business problems. This is especially critical as future managers are expected to correctly apply these critical economic concepts to help their particular company or business flourish and improve their bottom line position. This section briefly describes the topics usually covered in this course.

1. Description of the Economic Way of Thinking: This section usually involves an introduction to the course and refers to topics like marginal benefit and marginal costs, as well as using marginal decision-making rules, opportunity costs, and its importance in decision making.

2. Demand and Supply: This is the basic bread and butter of all economics courses. This section talks about consumer demand for products, producer supply of products and equilibrium prices, and also how prices change because of changes in the market conditions.

3. Production, Costs and Calculations: This section introduces the concepts of marginal and average productivity, provides an analysis of how they change and the relationship between productivity and costs. The concepts of short and long-run are introduced as also the different types of costs - fixed, variable and average and marginal measures. Factors that affect costs, like economies of scale and scope, are explored. 
4. Pricing and Elasticity: This section is probably the most difficult to understand but is also probably one of the most critical concepts for business managers. It explores the relationship between prices, elasticity and revenues and profits. It looks into ideas like optimal and actual markups, and price changes to change revenues and profits based on elasticity and Marginal Cost.

5. Market Structures: Another section that is critically important to understand for business managers, which deals with different market structures such as competitive markets, monopoly, and, most importantly because of its business applications, monopolistic competition and oligopoly. This section also deals with sustainable competitive advantage and the ways for businesses to keep their profitability for a while.

6. Strategic Behavior and Game Theory: This section is a continuation of a description of the market structure, Oligopoly, and uses the theories of games and strategic interactions to describe company strategies and payoffs from those strategies. In this section, bargaining and negotiations may also be covered. This topic has been gaining relative importance in the business curriculum because of a lot of interesting examples of strategic decision-making by companies and its applicability to a lot of industries and business situations with a small number of interacting agents.

7. Uncertainty, Economics of Information: This section broadly covers an appropriate solution to combating risk and uncertainty in business decision making, the role of auctions in resolving uncertainty, uncertainty about information and lack of complete information, in general, and the resulting problems, especially adverse selection and moral hazard. This section has a rich variety of practical applications in the business world, including all types of auctions, and also has widespread applications in the financial markets and human resource management.

These are the basic topics that are taught in almost all MBA level Managerial Economics courses, or any other economics courses that are substituted for it. Thus, any appropriate company profile or stories about their strategic decision-making should include at least some of these basic concepts. An instructor would thus be able to show to the students that in addition to each concept being applied in different businesses, firms may also apply different concepts at different points of time in their existence, thus strengthening the perception of importance of economics in the business world in the minds of the students.

\section{THE MEDIA PROFILES}

Two articles that are used in this particular class are "Success at Sea" by Stephanie Ponder, published in the February 2011 issue of the Costco Connection, and "Focused Growth" by Brooke Bates, published in the December 2010 issue of Smart Business Chicago. However, the particular articles - or the companies - are not important; the instructor can use any company profile that demonstrates the use of a number of different economic concepts to a real life business operation.

\section{Success at Sea}

This profile talks about a fishing and fish processing company located in Alaska and discusses the history of the company including its innovations, and points out its successes as a fish processing company and its history of sustainable endeavors. Listed below are some of the concepts of economics applied in the business model of the company:

1. The major innovation of the company was to manufacture a boat which could fish and process fish at the same time. This would be an application of economies of scope, where the simultaneous production of two services reduces costs to the business relative to them being produced separately. Here the boat catches the fish, immediately processes and freezes them (if applicable), thus removing from consideration an immediate journey back to the shore after the catch to process the fish. Thus, this method reduces costs dramatically. Also, the boat can now visit the most abundant areas and stay there until a satisfactory catch, without worrying about distance from a shore processing plant or time taken, since processing is done on board.

2. The second application of an economic concept is something we see in most successful business ventures the correct application of economies of scale. In this case, the company has found its perfect scale and is neither too big nor too small. They have expanded over time, but have expanded carefully to reap the benefits of scale economies. 
3. The company also performs strict quality control of its products and prides itself on being very responsive to customer feedback. This can allow it to differentiate itself from other fish processing companies on the basis of quality. This would be an application of product differentiation under monopolistic competition, where the economic concept is that differentiation of your product or service allows a business to charge a higher price than their competitors because the customers value your product more, thus making the demand for their product a little more inelastic, hence the higher price.

4. The company also has a major strategy of sustainable production. Thus, they always keep in mind never to over fish, thus keeping the supply of the product at an expected level and not have to deal with shortages or with the uncertainty of supply levels. Moreover, the company always harvests the right varieties in the right seasons leading to even less uncertainty about the supply. This strategy would be an application of the basic theories of supply and demand. The company ensures no disruptions to its supply and thus no uncertainty. As is well known, uncertainty hurts businesses; and moreover, if there is a shortage of fish, the prices would increase which might hurt the bottom line of the company since an elastic demand for fish would imply that the fall in quantity demand would not be proportionally compensated by the rise in prices.

5. The last application of an economic concept we see here is another one that is usually used by most successful firms - keeping their suppliers happy. By having interactions and personal relationships with their suppliers, the company is able to keep supply uncertainty down and it helps the company in the prices it negotiates with its suppliers, thus keeping costs down.

\section{Focused Growth}

Options Xpress is a Chicago-based online stockbroker for retail customers. The article talks about the core business of the company and how it measures its success and failures against how they are performing for their core. The basic economic concepts used in the company are the following:

1. Economies of scale and Scope. The company seeks to keep its growth at sustainable levels. It doesn't seek to grow too large because it fears that it will dilute its core business of providing an online brokerage for retail customers. It chooses not to expand into foreign exchange futures since that would be too different of a trading business from its current model. Thus, the company uses the economic concepts of Economies of Scale and avoids being caught by Diseconomies of Scope.

2. The company differentiates itself from its competitors by concentrating on its base business - providing an excellent online platform for retail customers. It takes customer feedback very seriously and thus has happy customers willing to pay the fees in exchange for personalized services.

3. The company keeps up with its current and future customers and keeps up with excellent analysis of the demand for its products. It thus uses the concepts of demand to figure out the extent to which they can grow and the prices they can charge

4. The company communicates regularly with its employees and avails their feedback before making important strategic decisions, thus keeping employees in the loop and happy. Happy employees imply greater productivity and fewer turnover of employees which always comes at a cost to the company, especially if the departing employee is very productive.

Thus, in both of the above company examples, the use of economic concepts is widespread. The idea of this paper is not to provide the actual company profiles or company strategy write ups in the media, but rather to point out that this technique could lead to a more engaged student body that will be able to apply economic concepts in their professional life.

\section{CONCLUSION}

This paper expands on a pedagogical technique that is used by the author in an MBA-level Managerial Economics class - the technique is that of using up-to-date examples to illustrate applications of economic concepts. In this paper, a similar technique of using a fully developed company profile in the media, or a media story about successful strategies pursued by a company, is described. This would lead to better student engagement in the material and a better understanding of the importance of the application of economic concepts to real life business situations. This should thus lead to further professional development of the students. This technique is one that is currently being used in the Managerial Economics class. 


\section{AUTHOR INFORMATION}

Indranil Ghosh is an Assistant Professor of Economics at the Graham School of Management at Saint Xavier University in Chicago. Previously he served as an Assistant Professor at Winston Salem State University, and as a Lecturer at Penn State Erie. He earned his Ph.D from Southern Methodist University. His current research interests are Applied Mechanism Design, Teaching Tools for Economics, Topics in Applied Business Economics and Economics of Entitlement Reform. His teaching interests are Managerial Economics and International Economics. He has published scholarly articles and book chapters in a variety of peer reviewed publications. E-mail: ghosh@sxu.edu

\section{REFERENCES}

1. Allgood, Sam, William Bosshardt, Wilbert van der Klaauw, and Michael Watts. 2004. "What Students Remember and Say about College Economics Years Later." American Economic Review, 94(2): 259-65.

2. Bates, Brooke, Focused Growth, How David Fisher grows Options Xpress by sticking to a core, Smart Business Chicago, December 2010.

3. Becker, William E.; Watts, Michael; Becker, Suzanne R., eds. Teaching Economics: More Alternatives to Chalk and Talk, Cheltenham, U.K. and Northampton, Mass.: Elgar, 2006.

4. Ponder, Stephanie E., Success at Sea, Quality and Sustainability are hallmarks of Trident Seafoods.

5. Simpkins, Scott; Maier, Mark. 2004. "Using Just In Time Teaching Techniques in the Principles of Economics Course.” Social Science Computer Review 22(4): 444-456.

6. Watts, Michael, and William E. Becker. 2005. "A Little More Than Chalk and Talk: Results from a Third National Survey of Teaching Methods in Undergraduate Economics Courses." http://www.aeaweb.org/annual_mtg_papers /2006/0106_0800_1201.pdf. 
NOTES 